\title{
Lifetime economic impact of the burden of childhood stunting attributable to maternal psychosocial risk factors in $\mathbf{1 3 7}$ low/middle-income countries
}

\author{
Mary C Smith Fawzi, ${ }^{1}$ Kathryn G Andrews, ${ }^{2}$ Günther Fink, ${ }^{3}$ Goodarz Danaei, ${ }^{2,4}$ \\ Dana Charles McCoy, ${ }^{5}$ Christopher R Sudfeld, ${ }^{2}$ Evan D Peet, ${ }^{6}$ Jeanne Cho, ${ }^{7}$ \\ Yuanyuan Liu, ${ }^{8}$ Jocelyn E Finlay, ${ }^{9}$ Majid Ezzati, ${ }^{10}$ Sylvia F Kaaya, ${ }^{11}$ \\ Wafaie W Fawzi ${ }^{2,4,12}$
}

\begin{abstract}
To cite: Smith Fawzi MC, Andrews KG, Fink G, et al. Lifetime economic impact of the burden of childhood stunting attributable to maternal psychosocial risk factors in 137 low/middle-income countries. BMJ Glob Health 2019;4:e001144. doi:10.1136/ bmjgh-2018-001144
\end{abstract}

Handling editor Seye Abimbola

Received 29 August 2018 Revised 13 November 2018 Accepted 17 November 2018

A) Check for updates

(C) Author(s) (or their employer(s)) 2019. Re-use permitted under CC BY-NC. No commercial re-use. See rights and permissions. Published by BMJ.

For numbered affiliations see end of article.

\section{Correspondence to} Dr Mary C Smith Fawzi; mary_smith-fawzi@hms. harvard.edu

\section{ABSTRACT}

Introduction The first 1000 days of life is a period of great potential and vulnerability. In particular, physical growth of children can be affected by the lack of access to basic needs as well as psychosocial factors, such as maternal depression. The objectives of the present study are to: (1) quantify the burden of childhood stunting in low/middle-income countries attributable to psychosocial risk factors; and (2) estimate the related lifetime economic costs.

Methods A comparative risk assessment analysis was performed with data from 137 low/middle-income countries throughout Asia, Latin America and the Caribbean, North Africa and the Middle East, and sub-Saharan Africa. The proportion of stunting prevalence, defined as $<-2$ SDs from the median height for age according to the WHO Child Growth Standards, and the number of cases attributable to low maternal education, intimate partner violence (IPV), maternal depression and orphanhood were calculated. The joint effect of psychosocial risk factors on stunting was estimated. The economic impact, as reflected in the total future income losses per birth cohort, was examined.

Results Approximately 7.2 million cases of stunting in low/ middle-income countries were attributable to psychosocial factors. The leading risk factor was maternal depression with 3.2 million cases attributable. Maternal depression also demonstrated the greatest economic cost at $\$ 14.5$ billion, followed by low maternal education ( $\$ 10.0$ billion) and IPV (\$8.5 billion). The joint cost of these risk factors was $\$ 29.3$ billion per birth cohort.

Conclusion The cost of neglecting these psychosocial risk factors is significant. Improving access to formal secondary school education for girls may offset the risk of maternal depression, IPV and orphanhood. Focusing on maternal depression may play a key role in reducing the burden of stunting. Overall, addressing psychosocial factors among perinatal women can have a significant impact on child growth and well-being in the developing world.

\section{INTRODUCTION}

Early childhood is a period of tremendous potential and vulnerability. In particular,

\section{Key questions}

What is already known?

- The first 1000 days of life is a period of significant potential as well as vulnerability; physical and psychosocial adversity can have a substantial impact on early childhood growth and development.

- Studies in a number of resource-limited settings have demonstrated associations between psychosocial risk factors, such as maternal depression and intimate partner violence (IPV), on childhood stunting.

\section{What are the new findings?}

- The present study advances this knowledge by estimating the effect of psychosocial risk factors on childhood stunting in 137 countries in the developing world-we observed that maternal depression resulted in the largest number of cases of childhood stunting (3.2 million), which was followed by low maternal education (2.9 million) and IPV (2.1 million).

- The joint number of childhood stunting cases attributed to these factors was 7.2 million and the cost of not addressing these factors was estimated to be $\$ 29.3$ billion for each birth cohort of children.

What do the new findings imply?

- The cost of inaction is substantial in terms of future revenue lost to economies in the developing world, and for the long-term health and well-being of children as they transition into adulthood.

- Advancing access to formal education for girls, addressing violence against women and increasing access to care for maternal depression have the potential to significantly reduce childhood stunting and enhance the health and well-being of future generations.

research has shown that the first 1000 days of life, prenatally through 2 years of age, are critical with respect to children's physical development. ${ }^{1}$ The rapid growth trajectories of the first 2 years of children's lives make infants and 
young children particularly vulnerable to disruptions in their environment. Food insecurity, poor complementary feeding, lack of potable water, poor housing conditions and the high burden of illness that accompanies chronic poverty create an environment that can negatively affect children's educational attainment and economic security in the long term. ${ }^{23}$

The limited resources available to children in low/ middle-income countries are often exacerbated by frequent exposure to psychosocial risk factors threatening healthy physical development. Psychosocial risk encompasses a broad range of factors including parental depression and other mental health problems, intimate partner violence (IPV), child abuse, parental use of alcohol and/or other substances particularly during pregnancy, low maternal education and orphanhood, among other factors. ${ }^{2}$ The combination of environmental and psychosocial adversity can result in 'toxic stress' for young children, inducing permanent harm on children's developmental trajectories. ${ }^{4}$

Although the impact of these psychosocial risk factors on children's physical development has been evaluated in epidemiological studies in a number of low/middle-income country settings, ${ }^{35}$ to date there has been no comprehensive analysis that quantifies the individual and combined effects of these factors at the population level in low/middle-income countries. Therefore, the primary goal of this study is to provide estimates of the impact of psychosocial risk factors on childhood physical growth. To do so, we estimate the proportion and number of stunting cases among children 2 years of age that are attributable to psychosocial risk factors in 137 low/ middle-income countries. The long-term economic costs related to the effects of these factors are also evaluated.

\section{METHODS}

We estimated the burden of stunting among children 2 years of age that is attributable to psychosocial risk factors in each of the 137 low/middle-income countries. Stunting was defined as $<-2$ SDs from the median height for age according to the WHO Child Growth Standards. ${ }^{6}$ The list of countries classified as low/middle income was based on the Global Burden of Disease, Injuries, and Risk Factors 2010 Study $^{7}$ (country list available in online supplementary appendix table 1). We used estimates of the prevalence of stunting among children under 5 years of age for each country as published from the 2011 Nutrition Impact Model Study (NIMS) ${ }^{8}$ To estimate the number and prevalence of stunting among children 2 years of age, we needed to adjust the NIMS estimates to be accurate for our age group of interest. To do so, we calculated the ratio of stunting among children 24-35 months of age: $0-59$ months of age using 104 surveys available from the WHO Global Database on Child Growth and Malnutrition. ${ }^{9}$ For the 33 countries without surveys, we used population-weighted subregional averages to generate a correction factor (additional description is available in online supplementary appendix). For the estimates of the population size of children 2 years of age we used the United Nations Population Division World Population Prospects 2015 Revision. ${ }^{10}$

\section{Identification of risk factors, effect sizes and exposure data sources}

The psychosocial risk factors identified for the study were based on what is currently known about psychological and social factors that can lead to 'toxic stress' and result in poor childhood growth and development. With regard to psychological factors, maternal depression, parental alcohol/substance abuse, IPV and child abuse are factors that place a child at risk of toxic stress. ${ }^{311}$ The social context, such as being an orphan or suffering from economic insecurity related to low parental education, can also place young children at risk of toxic stress and can lead to stunting. ${ }^{3} 12$ The psychosocial risk factors considered were: maternal depression, IPV, child abuse, parental use of alcohol, parental use of other addictive substances, low maternal education, low paternal education and orphanhood.

A comprehensive literature review of these risk factors was performed in PubMed by two master's degree level research assistants and was verified by the study's lead author. The following search terms were used: ('height' or 'length' or 'head circumference' or 'child growth' or 'infant growth' or 'stunted' or 'stunting' or 'heightfor-age') and ('maternal depression' or 'maternal depressive symptoms' or 'parental education' or 'maternal education' or 'paternal education' or 'mother's education' or 'father's education' or 'violence' or 'domestic violence' or 'IPV' or 'intimate partner violence' or 'child abuse' or 'childhood abuse' or 'childhood violence' or 'childhood neglect' or 'child neglect' or 'abused child' or 'abused children' or 'alcohol abuse' or 'alcohol use' or 'alcohol consumption' or 'substance use' or 'substance abuse' or 'marijuana' or 'cocaine' or 'drug use' or 'drug abuse' or 'orphans' or 'parental death' or 'maternal death' or 'paternal death' or 'orphan' or 'death of mother' or 'death of father' or 'maternal mortality'). The number of articles for each of the identified risk factors was as follows: maternal depression $(\mathrm{n}=74)$; IPV $(\mathrm{n}=20)$; child abuse $(n=318)$; parental use of alcohol $(n=1378)$; parental use of other addictive substances $(\mathrm{n}=1870)$; low maternal or paternal education $(n=728)$; and orphan$\operatorname{hood}(n=28)$.

Based on this literature search, only one study was identified that performed a formal meta-analysis on the association between maternal depression and childhood stunting. ${ }^{13}$ Since this was the only meta-analysis, studies that were based on analysis of Demographic and Health Survey (DHS) data across a broad range of low/ middle-income countries were used for other psychosocial variables, including low maternal education, ${ }^{14} \mathrm{IPV}^{15}$ and orphanhood. ${ }^{16}$ For other psychosocial risk factors that did not have a meta-analysis or DHS data across a number of low/middle-income countries, including 
Table 1 Sources of data on the psychosocial risk factors used in this analysis and their effect size for stunting

\begin{tabular}{|c|c|c|c|c|}
\hline Risk factors & Definition & $\begin{array}{l}\text { Evidence on effect size } \\
\text { for stunting }\end{array}$ & $\begin{array}{l}\text { OR } \\
(95 \% \mathrm{Cl})\end{array}$ & $\begin{array}{l}\text { Source of } \\
\text { exposure data }\end{array}$ \\
\hline $\begin{array}{l}\text { Low maternal } \\
\text { education }\end{array}$ & $\begin{array}{l}\text { Less than secondary } \\
\text { school education among } \\
\text { women }\end{array}$ & $\begin{array}{l}\text { Pooled analysis of } \\
\text { Demographic and Health } \\
\text { Surveys }^{14}\end{array}$ & $\begin{array}{l}\text { No maternal education versus at least } \\
\text { some secondary: } \\
1.27 \text { ( } 1.25 \text { to } 1.28) \\
\text { Some primary education versus at least } \\
\text { some secondary: } \\
1.20 \text { (1.18 to } 1.21)\end{array}$ & $\begin{array}{l}\text { Barro and } \text { Lee }^{17} \\
\text { IIASA }^{18}\end{array}$ \\
\hline Orphanhood & $\begin{array}{l}\text { Maternal, paternal or } \\
\text { double orphanhood } \\
\text { before age } 2\end{array}$ & $\begin{array}{l}\text { Pooled analysis of } \\
\text { Demographic and Health } \\
\text { Surveys }^{16}\end{array}$ & $\begin{array}{l}\text { Maternal orphanhood: } \\
1.3(1.2 \text { to } 1.4) \\
\text { Paternal orphanhood: } 0.97 \text { (0.92 to } 1.03) \\
\text { Double orphanhood: } \\
1.2(0.9 \text { to } 1.6)\end{array}$ & $\begin{array}{l}\text { Spectrum } \\
\text { (Futures Group) }^{44}\end{array}$ \\
\hline $\begin{array}{l}\text { Intimate partner } \\
\text { violence }\end{array}$ & $\begin{array}{l}\text { Physical and/or sexual } \\
\text { violence against a woman } \\
\text { by her partner }\end{array}$ & $\begin{array}{l}\text { Pooled analysis of } \\
\text { Demographic and Health } \\
\text { Surveys }{ }^{15}\end{array}$ & $1.13(1.10$ to 1.16$)$ & Devries et $a l^{45}$ \\
\hline $\begin{array}{l}\text { Maternal } \\
\text { depression }\end{array}$ & $\begin{array}{l}\text { Major depressive disorder } \\
\text { among mothers }\end{array}$ & $\begin{array}{l}\text { Meta-analysis of four } \\
\text { longitudinal observational } \\
\text { studies }^{13}\end{array}$ & 2.0 (1.0 to 3.9$)$ & Ferrari et al ${ }^{19}$ \\
\hline
\end{tabular}

IIASA, International Institute for Applied Systems Analysis.

child abuse, parental use of alcohol and parental substance abuse, insufficient information was available on exposure prevalence to include them in the study. In addition, paternal education was not included in the analysis given the limited information on the relationship of this factor with stunting. Therefore, the four psychosocial risk factors included in this study were: (1) maternal depression; (2) IPV; (3) maternal education; and (4) orphanhood.

Our analysis also required estimates of the prevalence of exposure to each of the four psychosocial risk factors from as near to 2010 as possible for 137 countries. We derived these estimates from the most recent published literature and available databases with high country coverage. Estimates of maternal educational attainment were available for 109 low/middle-income countries (28 countries, primarily small island nations, had missing values) from the Barro and Lee ${ }^{17}$ and the Education, Reconstruction and Projections databases. ${ }^{18}$ For maternal depression, estimates were available from the Global Burden of Disease Study for 136 countries. ${ }^{19}$ For countries with missing exposure data for these two risk factors, available estimates from within the same subregion or region were averaged and used as the country-level estimates. For IPV, exposure estimates were only available at the regional level, and for orphanhood, results were available for only 45 countries, so the analysis was limited to this set of countries. See table 1 for the operational definition of the included risk factors and sources of data on exposure and effect sizes.

\section{Statistical methods}

We estimated the population attributable fraction (PAF) of stunting, which quantifies the proportion of stunting prevalence (or cases) attributable at the population level to the risk factor of interest. ${ }^{2021}$ These methods are widely used for estimating the burden of disease attributable to risk factors independent from one another (holding other risk factors constant), as described elsewhere. ${ }^{22}$ Estimating PAFs requires data on the exposure prevalence of the risk factor of interest and the relative risk (RR; here approximated by the OR) of stunting given exposure to the risk. The formula is as follows:

$$
P A F=\frac{\sum_{i} P_{i}\left(R R_{i}-1\right)}{\sum_{i} P_{i}\left(R R_{i}-1\right)+1}
$$

where $R R_{i}$ is the relative risk (or OR) of stunting comparing category $i$ with the reference (or optimal exposure) category and $P_{i}$ is the prevalence of exposure to the risk factor.

To estimate the combined impact of maternal depression, IPV and low maternal education we used a simple relationship to estimate the joint PAF while preventing 'double counting', as a single case of stunting can be attributed to more than one risk factor. ${ }^{14}$ The relationship is captured by the formula below which assumes that there is no correlation and no effect modification for RRs.

$$
P A F_{j}=1-\prod_{i=1}^{R}\left(1-P A F_{i}\right)
$$

where $P A F_{i}$ is an individual PAF for a risk in group $j$, and all individual risk factors (from 1 to $R$ ) in group $j$ are combined using the formula above to estimate $P A F$, which is the fraction of stunting attributable to all the risk factors in group $j$.

Some of the effect of IPV on stunting may be mediated through maternal depression. ${ }^{23}{ }^{24}$ In order to account for this, we calculated the direct effect of IPV on stunting (ie, not through maternal depression) by removing $25 \%$ of the excess RR of IPV. Since the precise magnitude of the mediation of IPV through maternal depression is 
unknown, we present online supplementary appendix table 2 which shows the results of a sensitivity analysis that varies the proportion of the effect of IPV on stunting that is mediated through maternal depression.

We estimated the prevalence of stunting and number of stunting cases attributable to a given risk factor by multiplying the corresponding PAF by the prevalence or number of stunting cases among children age 2 in each country. We estimated the prevalence of stunting among children age 2 as described above. Data on population of children at age 2 (ie, 24-35 months) were from the United Nations Population Division. ${ }^{25}$

To quantify the economic burden caused by these early life growth restrictions, we followed the model developed in Fink $e t a t^{26}$ and computed the net present value of total future income losses per birth cohort in each country attributable to each risk factor. Given that our risk factor analysis focused on stunting as an outcome whereas the paper cited above focused on height-for-age z-score (HAZ), we relied on the fact that there is a roughly linear relationship between stunting prevalence and average HAZ (see online supplementary appendix for method description). To assess uncertainty we used a bootstrapping algorithm and generated 1000 independent random draws from each input to estimate PAFs, attributable stunting and economic returns for each random draw. The $95 \%$ CIs were calculated by using the 2.5th and the 97.5th percentiles of the draws. Additional detail on statistical analysis is provided by Danaei $e t a l .^{22}$ STATA SE V.13.1 was used for analysis.

\section{RESULTS}

Overall, the combined effect of maternal depression, IPV and low maternal education indicated that 7.2 million (95\% CI 4.4 to 11.5 million) cases of stunting among 2 year-olds were attributable to psychosocial risks (of 44 million stunting cases among children aged 2 overall in the developing world) (figure 1). Among these factors, maternal depression was the leading risk factor with 3.2 million cases (95\% CI -22000 to 7.8 million). The risk factor with the second highest number of cases was low maternal education, with 2.9 million (95\% CI 2.6 to 3.1 million), while IPV was associated with 2.1 million (95\% CI 1.6 to 2.6 million) cases of stunting globally (table 2).

Regionally, South Asia and sub-Saharan Africa demonstrated the highest number of cases of child stunting attributable to maternal depression, IPV and low maternal education jointly (both at 2.8 million; 95\% CI for South Asia 1.7 to 4.5 million; $95 \%$ CI for sub-Saharan

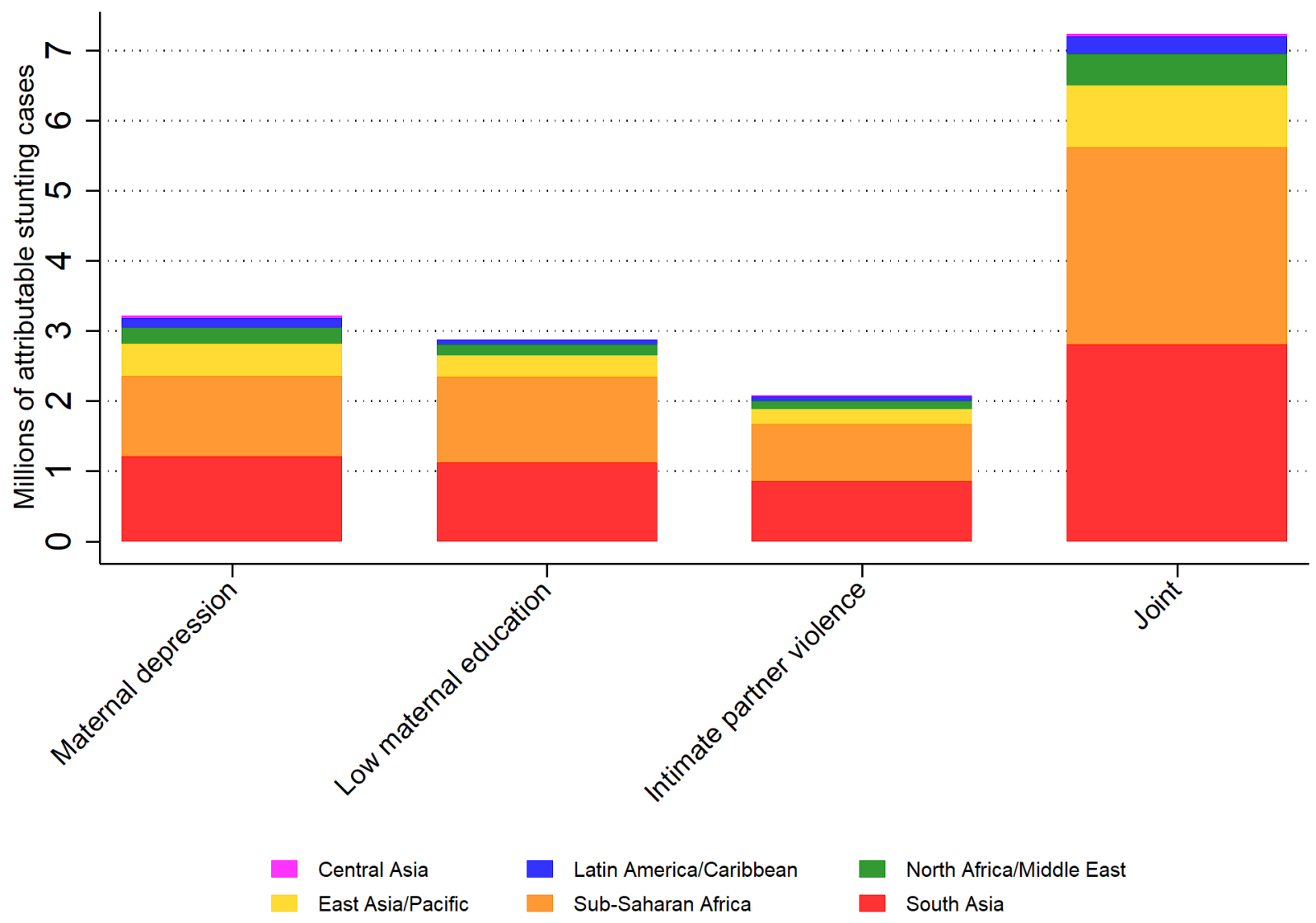

Figure 1 The number of attributable stunting cases in children aged 2 in 137 low/middle-income countries in 2010 , by risk factor and region. Effects are not additive because each case of stunting can be attributed to more than one risk factor. 


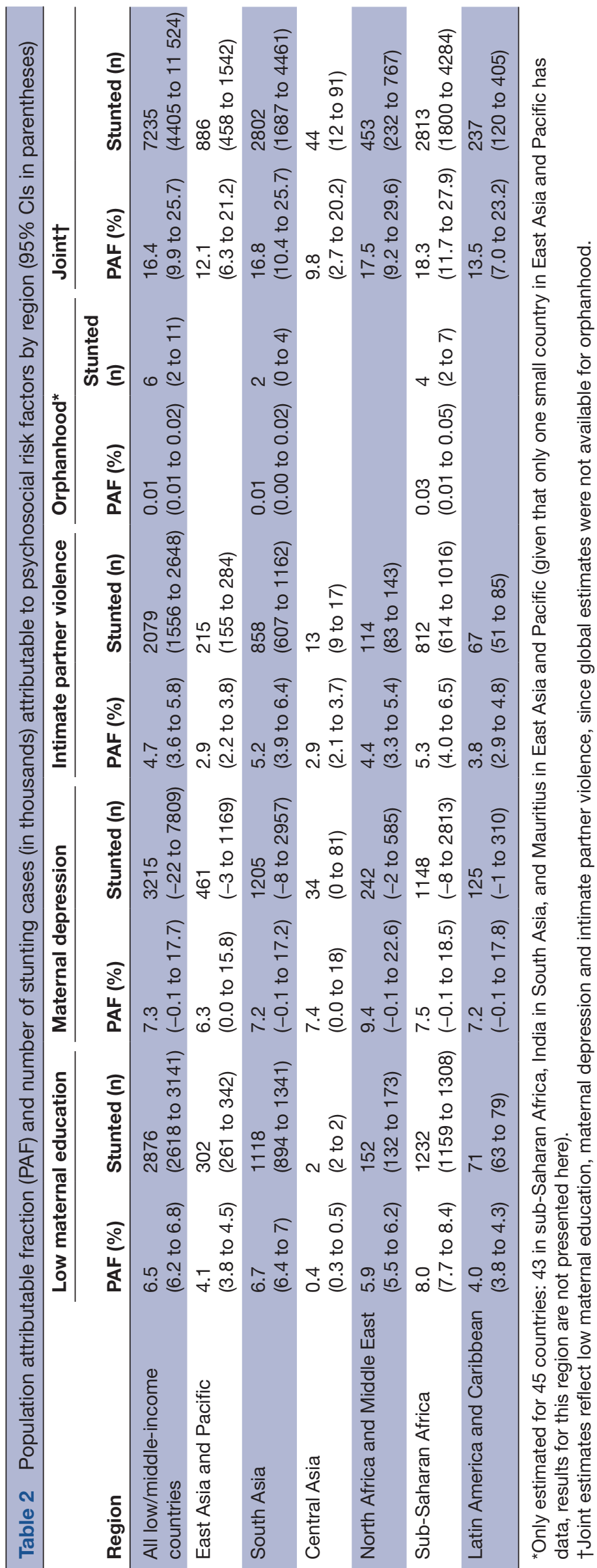



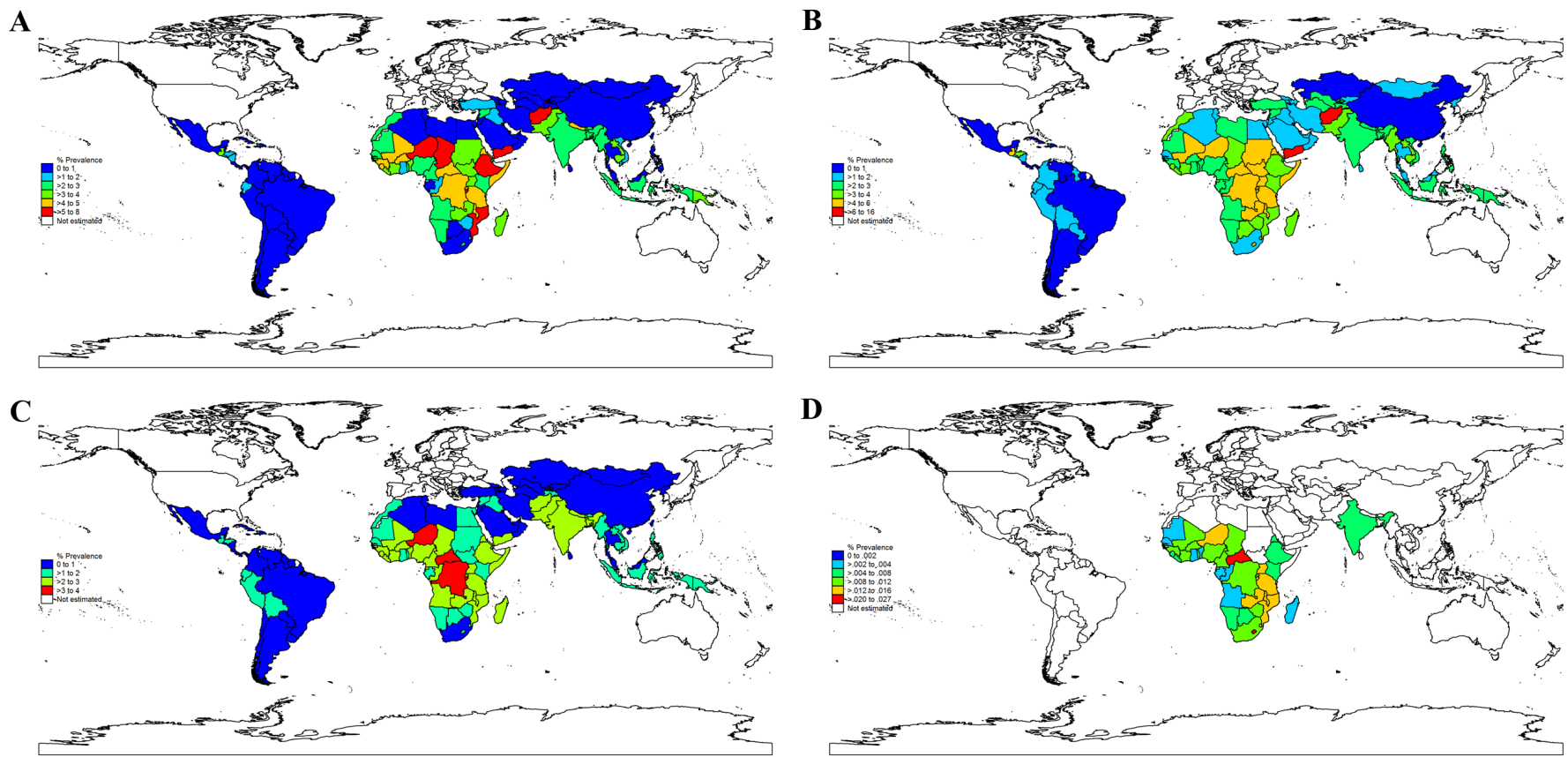

Figure 2 Stunting prevalence attributable to (A) low maternal education, (B) maternal depression, (C) intimate partner violence and (D) orphanhood.

Africa 1.8 to 4.3 million). For maternal depression, the largest number of attributable stunting cases was in South Asia (1.2 million; 95\% CI -8000 to 3.0 million) and sub-Saharan Africa (1.1 million; $95 \%$ CI -8000 to 2.8 million). South Asia had the largest number of cases of stunting attributable to IPV, and sub-Saharan Africa had the highest number of cases attributable to low maternal education (table 2).

Figure 2A demonstrates the stunting prevalence attributable to low maternal education, with Niger, Burundi, Ethiopia, Afghanistan and Yemen experiencing the highest burden, ranging from $5.5 \%$ to $7.1 \%$. These countries were followed in magnitude by Chad, Mozambique, Guinea, Rwanda and Central African Republic, which had attributable prevalence estimates of $4.7 \%-5.2 \%$. The pattern was somewhat different for maternal depression. Afghanistan demonstrated the highest stunting prevalence attributable to depression $(15.8 \%$ (95\% CI $-0.1 \%$ to $32.1 \%)$ ), followed by Yemen $(6.5 \%$ (95\% CI $-0.05 \%$ to $15.4 \%)$ ). A significant burden of maternal depression on stunting was observed throughout sub-Saharan Africa and parts of South and Southeast Asia, ranging from 2\% to 6\% (figure 2B). For IPV, Central African Republic, Democratic Republic of the Congo, Niger and Burundi and had the highest attributable prevalence $(3 \%-4 \%)$. These were followed in magnitude by countries largely in sub-Saharan Africa (eg, Angola, Eritrea, Ethiopia) and South Asia (eg, Afghanistan) (figure 2C). Lesotho, Central African Republic, Swaziland and Zambia demonstrated the highest prevalence attributable to orphanhood (all greater than $0.02 \%$ ). This was closely followed by Mozambique, Malawi and Niger $(0.017 \%-0.019 \%)$ (figure 2D).
Figure 3 shows the combined effect of maternal depression, IPV and low maternal education on stunting. Afghanistan demonstrated the highest overall burden of stunting related to these risk factors (attributable prevalence $21.5 \%$; $95 \%$ CI $7.5 \%$ to $36.4 \%$ ), followed by Yemen (13.3\%; $95 \%$ CI $7.2 \%$ to $21.9 \%)$, Niger $(13.2 \%$; $95 \%$ CI $8.8 \%$ to $19.5 \%)$ and Burundi $(13.1 \%$; $95 \%$ CI $8.0 \%$ to $20.2 \%)$. A number of sub-Saharan African countries, such as Eritrea, Central African Republic, Rwanda, Tanzania, Ethiopia and the Democratic Republic of the Congo, demonstrated an attributable prevalence of stunting related to these joint effects ranging from $10.5 \%$ to $11 \%$. Online supplementary appendix 3 provides country-level results.

For maternal depression, the overall estimate for the economic cost by cohort was $\$ 14.5$ billion for low/ middle-income countries per birth cohort (95\% CI -0.11 to 36.8 billion) (table 3). South Asia demonstrated the greatest cost (\$3.6 billion), followed by sub-Saharan Africa (\$3.0 billion). For low maternal education, the estimated cost per cohort was approximately $\$ 10.0$ billion (95\% CI 8.0 to 12.1 billion). For IPV, the overall cost for low/middle-income countries was estimated at $\$ 8.5$ billion (95\% CI 6.0 to 11.6 billion); regionally the highest costs related to IPV were for South Asia ( $\$ 2.7$ billion) and sub-Saharan Africa ( $\$ 2.0$ billion). For the cost of orphanhood (which was limited to data from sub-Saharan Africa, India and Mauritius), sub-Saharan Africa's estimate of cost by cohort was $\$ 14$ million. Overall, the joint cost of maternal depression, IPV and low maternal education was $\$ 29.3$ billion ( $95 \%$ CI 15.3 to 50.9 billion) per birth cohort. Additional detail is included in the online appendix figures 1-3 on: (1) stunting prevalence 


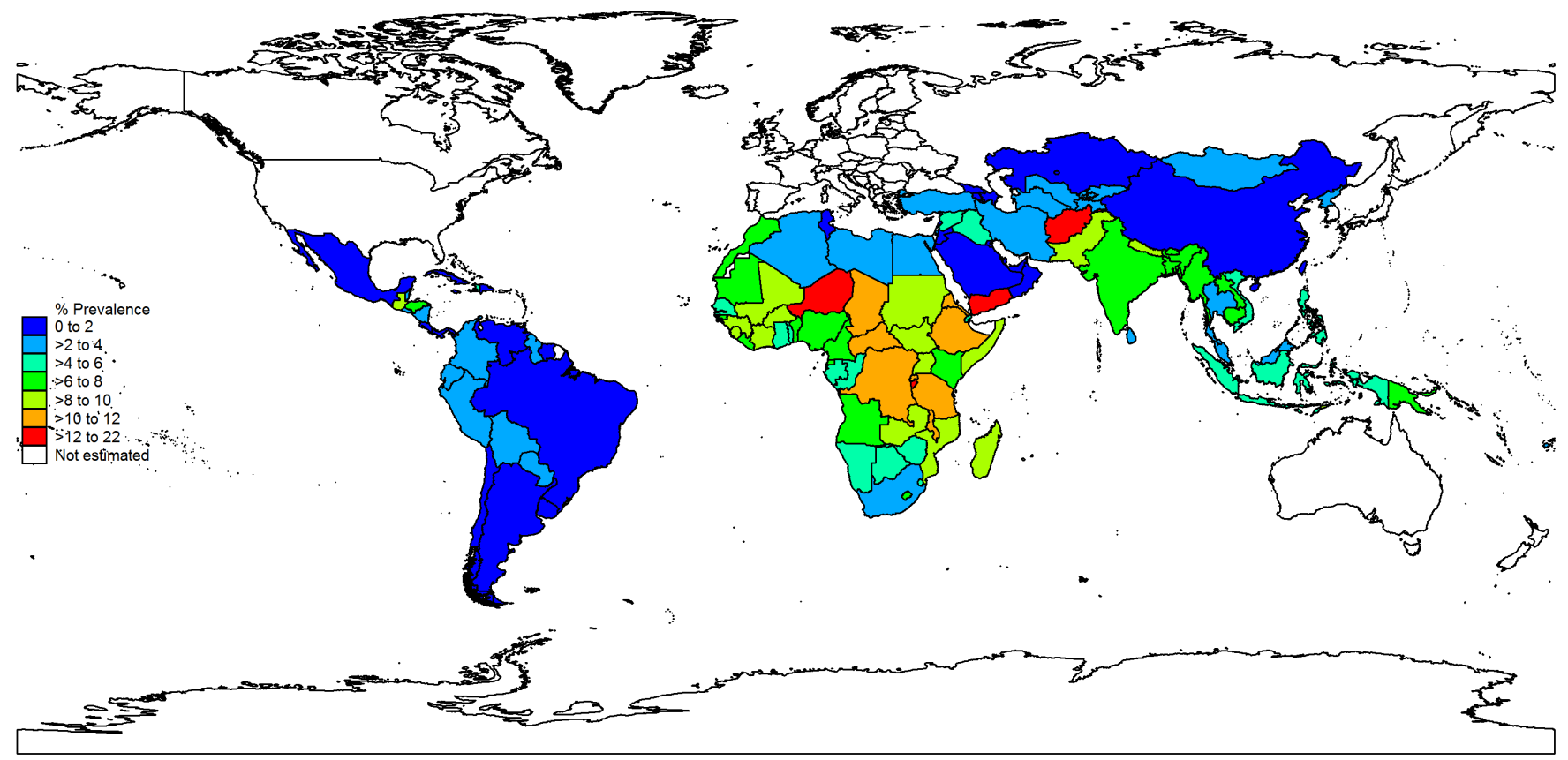

Figure 3 Stunting prevalence attributable to the combined effect of maternal depression, intimate partner violence and low maternal education.

attributable to combined effect of psychosocial risk factors; (2) PAF of stunting attributable to risk factors, individually and jointly; and (3) relationship of heightfor-age $\mathrm{Z}$ scores and prevalence of stunting.

\section{DISCUSSION}

The results indicate that 7.2 million cases of child stunting in low/middle-income countries are jointly attributable to low maternal education, IPV and maternal depression. The most vulnerable regions with respect to the burden of psychosocial risk factors on excess stunting among children 2 years of age are South Asia and sub-Saharan Africa. Not surprisingly, these regions in general are coping with relatively greater levels of poverty compared with other developing regions, ${ }^{25}$ and suffer from high rates of stunting and exposure to psychosocial risk factors. Low maternal education, which is often coupled with poverty and food insecurity, ${ }^{27}$ demonstrated a significant impact within this group of psychosocial risk factors. These findings are consistent with studies that have examined associations of stunting with maternal depression, IPV and maternal education. ${ }^{13-15}$

The lifetime economic cost of neglecting these psychosocial risk factors in low/middle-income countries is significant with an estimated overall joint cost of maternal depression, IPV and low maternal education of $\$ 29.3$ billion per birth cohort. These estimates of the financial burden associated with these risk factors are based on tracing their relationship with stunting through to lifetime wage income losses, and are driven by the magnitude of the burden of the risk factors, number of stunted children, stunting's relationship with schooling attainment, schooling's impact on wages and the expected lifetime wage income of individuals in each country. This complex pathway demonstrates how exposure to psychosocial risks early in life can result in large accumulated downstream effects at the population level.

Given that our results show that low maternal education and IPV are responsible for a significant excess burden of stunting among 2-year-old children, gender inequality may play a role in childhood stunting. ${ }^{28-30}$ Correspondingly, although there are many potential precipitating factors related to maternal depression, IPV is one key variable. ${ }^{1524}$ In a recent analysis of DHS data from 29 low/middle-income countries, the overall prevalence of IPV (physical and/or sexual abuse) was over $30 \% .^{15}$ Investment in secondary school education for girls may serve as a preventive mechanism for IPV. ${ }^{31}$ This is critical, since it is very difficult to leave an abusive relationship. However, there is some evidence that IPV can be reduced through advancing income- generating initiatives for women. ${ }^{32}$ Persistent challenges in access to education and economic opportunities promote gender inequality; this can create the context for higher maternal mortality resulting in orphanhood, since women may have less agency to access antenatal care and delivery with a skilled birth attendant. ${ }^{33}$

In addition to access to secondary education among girls, another potential intervention to offset the excess burden of stunting related to psychosocial risks is to provide prevention services and treatment for depression among perinatal women. Increasing access to formal education for girls may potentially reduce the risk of IPV and prevent depression among young women. ${ }^{34} 35$ In addition, there is increasing evidence that maternal depression can be readily identified ${ }^{36}$ and effectively 
Table 3 Lifetime economic cost (US\$ millions per cohort) of psychosocial risk factors by subregion for the cohorts of children born in 2010 (95\% Cls in parentheses)

\begin{tabular}{|c|c|c|c|c|c|}
\hline Subregion & $\begin{array}{l}\text { Cohort size } \\
\text { (millions) }\end{array}$ & $\begin{array}{l}\text { Low maternal } \\
\text { education }\end{array}$ & $\begin{array}{l}\text { Maternal } \\
\text { depression }\end{array}$ & $\begin{array}{l}\text { Intimate partner } \\
\text { violence }\end{array}$ & Joint \\
\hline $\begin{array}{l}\text { All low/middle-income } \\
\text { countries }\end{array}$ & 122.9 & $\begin{array}{l}9966 \\
\text { (7954 to 12134) }\end{array}$ & $\begin{array}{l}14467 \\
(-110 \text { to } 36791)\end{array}$ & $\begin{array}{l}8494 \\
(6043 \text { to } 11555)\end{array}$ & $\begin{array}{l}29337 \\
\text { (15333 to } 50946)\end{array}$ \\
\hline Asia, Central & 1.8 & $\begin{array}{l}12 \\
(8 \text { to } 16)\end{array}$ & $\begin{array}{l}162 \\
(-1 \text { to } 419)\end{array}$ & $\begin{array}{l}67 \\
(42 \text { to } 100)\end{array}$ & $\begin{array}{l}219 \\
(60 \text { to } 479)\end{array}$ \\
\hline Asia, East & 17.1 & $\begin{array}{l}459 \\
\text { (286 to } 651)\end{array}$ & $\begin{array}{l}995 \\
(-6 \text { to } 2690)\end{array}$ & $\begin{array}{l}452 \\
\text { (218 to } 807)\end{array}$ & $\begin{array}{l}1754 \\
\text { (688 to } 3439)\end{array}$ \\
\hline Asia, South & 36.7 & $\begin{array}{l}3469 \\
(2520 \text { to } 4566)\end{array}$ & $\begin{array}{l}3588 \\
(-26 \text { to } 9340)\end{array}$ & $\begin{array}{l}2699 \\
\text { (1738 to } 3858)\end{array}$ & $\begin{array}{l}8591 \\
(4850 \text { to } 14233)\end{array}$ \\
\hline Asia, Southeast & 12.1 & $\begin{array}{l}1050 \\
\text { (763 to 1396) }\end{array}$ & $\begin{array}{l}1561 \\
(-12 \text { to } 3929)\end{array}$ & $\begin{array}{l}707 \\
\text { (486 to } 988)\end{array}$ & $\begin{array}{l}2997 \\
\text { (1467 to } 5353)\end{array}$ \\
\hline Caribbean & 0.7 & $\begin{array}{l}34 \\
\text { (25 to } 44)\end{array}$ & $\begin{array}{l}85 \\
(-1 \text { to } 220)\end{array}$ & $\begin{array}{l}37 \\
(24 \text { to } 53)\end{array}$ & $\begin{array}{l}142 \\
\text { (58 to } 273)\end{array}$ \\
\hline Latin America, Andean & 1.2 & $\begin{array}{l}81 \\
(62 \text { to } 104)\end{array}$ & $\begin{array}{l}174 \\
(-1 \text { to } 442)\end{array}$ & $\begin{array}{l}127 \\
\text { (88 to } 174)\end{array}$ & $\begin{array}{l}336 \\
(166 \text { to } 595)\end{array}$ \\
\hline Latin America, Central & 4.7 & $\begin{array}{l}827 \\
\text { (562 to } 1143 \text { ) }\end{array}$ & $\begin{array}{l}1424 \\
(-16 \text { to } 3865)\end{array}$ & $\begin{array}{l}913 \\
\text { (530 to } 1429)\end{array}$ & $\begin{array}{l}2831 \\
\text { (1307 to } 5398)\end{array}$ \\
\hline Latin America, Southern & 1.0 & $\begin{array}{l}51 \\
(26 \text { to } 79)\end{array}$ & $\begin{array}{l}136 \\
(-1 \text { to } 372)\end{array}$ & $\begin{array}{l}55 \\
(26 \text { to } 100)\end{array}$ & $\begin{array}{l}222 \\
\text { (79 to } 474)\end{array}$ \\
\hline Latin America, Tropical & 3.3 & $\begin{array}{l}461 \\
\text { (274 to } 672)\end{array}$ & $\begin{array}{l}1027 \\
(-6 \text { to } 2749)\end{array}$ & $\begin{array}{l}432 \\
\text { (231 to } 687 \text { ) }\end{array}$ & $\begin{array}{l}1739 \\
\text { (670 to } 3498)\end{array}$ \\
\hline North Africa/Middle East & 10.4 & $\begin{array}{l}1072 \\
\text { (813 to 1366) }\end{array}$ & $\begin{array}{l}2308 \\
(-17 \text { to } 5603)\end{array}$ & $\begin{array}{l}1018 \\
\text { (688 to } 1386)\end{array}$ & $\begin{array}{l}3936 \\
(1750 \text { to } 7113)\end{array}$ \\
\hline Oceania & 0.3 & $\begin{array}{l}47 \\
\text { (31 to } 66)\end{array}$ & $\begin{array}{l}40 \\
(0 \text { to } 104)\end{array}$ & $\begin{array}{l}24 \\
(13 \text { to } 38)\end{array}$ & $\begin{array}{l}100 \\
(55 \text { to } 171)\end{array}$ \\
\hline Sub-Saharan Africa, Central & 4.3 & $\begin{array}{l}284 \\
(209 \text { to } 367)\end{array}$ & $\begin{array}{l}329 \\
(-3 \text { to } 844)\end{array}$ & $\begin{array}{l}312 \\
(207 \text { to } 446)\end{array}$ & $\begin{array}{l}792 \\
\text { (443 to } 1321)\end{array}$ \\
\hline Sub-Saharan Africa, East & 13.5 & $\begin{array}{l}1094 \\
\text { (885 to 1335) }\end{array}$ & $\begin{array}{l}1134 \\
(-9 \text { to } 2870)\end{array}$ & $\begin{array}{l}627 \\
(441 \text { to } 846)\end{array}$ & $\begin{array}{l}2530 \\
\text { (1428 to } 4232)\end{array}$ \\
\hline Sub-Saharan Africa, Southern & 1.8 & $\begin{array}{l}240 \\
\text { (181 to } 307)\end{array}$ & $\begin{array}{l}768 \\
(-6 \text { to } 1962)\end{array}$ & $\begin{array}{l}405 \\
(269 \text { to } 587)\end{array}$ & $\begin{array}{l}1268 \\
\text { (512 to 2462) }\end{array}$ \\
\hline Sub-Saharan Africa, West & 13.9 & $\begin{array}{l}785 \\
\text { (622 to } 969)\end{array}$ & $\begin{array}{l}736 \\
(-6 \text { to } 1945)\end{array}$ & $\begin{array}{l}617 \\
(423 \text { to } 868)\end{array}$ & $\begin{array}{l}1882 \\
\text { (1126 to } 3053)\end{array}$ \\
\hline
\end{tabular}

treated through services provided by trained lay counsellors. ${ }^{37}$ More recently, a meta-analysis of strategies to treat maternal depression through the use of non-specialist community health workers found that maternal depression could be effectively treated in resource-limited settings. In addition to a reduced burden of maternal depression, this review also demonstrated an improvement in infant growth which in the long term can result in improved educational attainment as well as economic and food security in adulthood. ${ }^{37}$ The key issues are to use evidence-based approaches and to ensure the integrity of the intervention through appropriate training, implementation and supervision. Although IPV may precede depression, treatment of maternal depression can also potentially reduce the recurrence of IPV. Positive coping skills often attained through depression treatment can be used to leave abusive relationships or use problem solving/communication skills to address IPV within the context of the relationship. In addition, addressing maternal depression can also have an effect on more proximal risk factors for stunting, such as poverty and food insecurity, which may be on the pathway between maternal depression and stunting. ${ }^{38-40}$

Despite the fact that treatment strategies for depression have demonstrated to be effective and at relatively low cost when implemented by lay counsellors, ${ }^{37}$ the cost of not treating depression can be quite high. This is demonstrated by the current study that found an excess number of cases of childhood stunting in developing countries of 3.2 million and $\$ 14.5$ billion in unearned wages attributable to maternal depression. There are also a number of other repercussions of untreated maternal depression, including reduced cognitive development of children possibly related to less stimulation provided by the mother. ${ }^{5}$ If the woman's income is needed for the household, the mother may not have the capacity 
to work if depression is not addressed. In resource-limited households, this may have a direct impact on food security for the family. ${ }^{41}$ Given these contextual issues in resource-limited settings, linking maternal education and entrepreneurship programmes to depression treatment interventions may result in better overall well-being of depressed perinatal women and their children.

Overall, exposure to psychosocial risk factors, including low maternal education, IPV and maternal depression, can result in more than 7.2 million cases of early childhood stunting per birth cohort in developing countries. These findings have significant policy implications. If left unaddressed, the estimated economic cost for future generations is substantial. A number of strategies exist to address these risk factors. One approach that may have a broad impact is increasing access to secondary education among girls. This may offset the risk of other psychosocial risk outcomes through potential prevention of IPV and maternal depression, since increasing access to education among women can to some extent address the pervasive gender inequality that exists throughout the world. Increase in access to secondary education may also increase women's agency, enabling them to attain reproductive health services that may serve to prevent maternal mortality.

However, upstream approaches such as increasing access to secondary education and preventing maternal mortality will not be sufficient. Given the high burden of maternal depression and IPV, there is a critical role in providing treatment and prevention services. If left unaddressed, in some cases children may be orphaned by IPV and maternal depression, which in turn can lead to more excess cases of stunting. These psychosocial risk factors can create a downward spiral for women and their young children. However, addressing the issues upstream through greater access to education for girls, as well as through the necessary downstream approaches of advancing services for maternal depression and IPV, may offset this excess burden of stunting and potentially result in greater educational attainment, economic security and quality of life in the long term for women and their children in resource-limited settings.

\section{Limitations}

There are a number of limitations in this study. The estimate of exposure to maternal depression was based on the prevalence of depression among women of reproductive age. This could lead to a bias in potentially underestimating the stunting prevalence related to maternal depression; however, in settings of high fertility this bias is expected to be fairly small. For orphanhood, information on exposure was only available for 45 countries, which does not allow us to generate global or joint estimates. IPV exposure data were only available at the regional level and the prevalence of IPV may be underestimated, given the risk involved for women if it is reported.

The prevalence of stunting among children age 2 years was estimated by generating conversion factors, which add an additional level of uncertainty. In addition, stunting defined as <-2 SD HAZ may not fully capture linear growth faltering and may be an underestimate of impaired child growth. ${ }^{42}$ As all effect sizes were reported as ORs, we assumed that they approximated the RR which will lead to an overestimate of the PAF (and a resulting overestimate of the effect of these risk factors on stunting). Unfortunately, the required information is not available to correct this bias. While the ORs used in this analysis are derived from studies conducted in low/middle-income countries (our area of interest), we assumed that they do not vary by region. Without country-specific meta-analyses generating reliable effect sizes, further refinement of this assumption is not possible; however, not only is this a common assumption, ${ }^{21}$ multicountry studies of other childhood risk factors suggest that these effect sizes may not vary substantially by context. ${ }^{43}$ In addition, calculation of PAF suggests there is a causal association between the risk factors included in this study and stunting.

Although we cannot assert a direct and immediate causality of individual risk factors, there is sufficient information that these factors contribute to early childhood 'toxic stress', which has demonstrated a significant impact on early child growth and development and supports the inferences made in the study. Uncertainty for the exposures of low maternal education and orphanhood was not available, which means the CIs reported here are underestimated. Although we accounted for the possible mediating effect of maternal depression on the association of IPV and stunting, the potential mediation of IPV on the impact of low maternal education on stunting was not accounted for, given lack of evidence on how much of the effect is indeed mediated. In addition, our estimation of the economic burden associated with each risk factor was modelled only through its impact on stunting, stunting's impact on schooling attainment and schooling's relationship with lifetime wage earnings; we did not estimate the economic impact of risk factors through other pathways. Finally, although we examined the risk factors in terms of burden on childhood stunting, we did not analyse the long-term economic gain of specific treatment or prevention strategies.

\section{CONCLUSION}

In conclusion, the cost of not addressing psychosocial risk factors, such as maternal depression, IPV and limited access to formal education for young women, is substantial in the long term. As a result, there are significant policy implications-in addition to adequate access to mental healthcare and IPV services, broader multisectoral programmes to increase access to secondary education among girls and reduce gender inequality are essential. These initiatives may promote health, quality of life and well-being of women and their children throughout the developing world, and have the potential to advance economic security for future generations. 


\section{Author affiliations}

${ }^{1}$ Department of Global Health and Social Medicine, Harvard Medical School, Boston, Massachusetts, USA

${ }^{2}$ Department of Global Health and Population, Harvard TH Chan School of Public Health, Boston, Massachusetts, USA

${ }^{3}$ Swiss Tropical and Public Health Institute, University of Basel, Basel, Switzerland

${ }^{4}$ Department of Epidemiology, Harvard TH Chan School of Public Health, Boston, Massachusetts, USA

${ }^{5}$ Harvard Graduate School of Education, Cambridge, Massachusetts, USA

${ }^{6}$ RAND, Pittsburgh, Pennsylvania, USA

${ }^{7}$ Sala Institute for Child and Family Centered Care at NYU Langone Health, New York City, New York, USA

${ }^{8}$ Health Science Center, University of Texas School of Public Health, Houston, Texas, USA

${ }^{9}$ Harvard Center for Population and Development Studies, Harvard TH Chan School of Public Health, Cambridge, Massachusetts, USA

${ }^{10}$ Department of Epidemiology and Biostatistics, MRC-HPA Centre for Environment and Health, Imperial College London, London, UK

${ }^{11}$ Department of Psychiatry and Mental Health, Muhimbili University of Health and Allied Sciences, Dar es Salaam, Tanzania

${ }^{12}$ Department of Nutrition, Harvard TH Chan School of Public Health, Boston, Massachusetts, USA

Acknowledgements We acknowledge all of our colleagues who supported the development of this manuscript. In particular, we thank Maureen Black, Makenzie Keene, Angela Leocata, Jeffrey Lienert, Kai Young Park, Pamela Surkan and Carolina Tavárez. We thank Dr John Stover for sharing the estimates of orphanhood. In addition, we express our gratitude to Grand Challenges Canada for supporting this work (No 0073-03). YL was supported by the UTHealth Innovation for Cancer Prevention Research Training Program Pre- or Post-doctoral Fellowship (Cancer Prevention and Research Institute of Texas grant number RP160015) at the time of submission.

Contributors MCSF drafted the manuscript and contributed to study concept and design, statistical analysis and interpretation of data. KGA conducted the statistical analysis, drafted the manuscript and contributed to study concept and design as well as interpretation of data. GF and GD contributed to study concept and design, drafting the manuscript, statistical analysis and interpretation of data. DCMC, EDP, JC, YL and JEF contributed to drafting the manuscript and interpretation of data. CRS, ME, SFK and WWF contributed to study concept and design, drafting the manuscript and interpretation of data. WWF obtained funding for the study. All authors had full access to the data (including statistical reports and tables) and take responsibility of the integrity of the data and the accuracy of the data analysis.

Funding Grand Challenges Canada (No 0073-03) funded the research.

Disclaimer The funder was not involved in any aspect of the study design, data analysis and interpretation, writing the report, or the decision to submit the article for publication. All authors are independent of the funder. The content is solely the responsibility of the authors and does not necessarily represent the official views of the Cancer Prevention and Research Institute of Texas.

Competing interests None declared.

Patient consent for publication Not required.

Ethics approval Data for the current study are at the aggregate level and no individual-level data are analysed. Therefore, institutional review board approval is not required for this study.

Provenance and peer review Not commissioned; externally peer reviewed.

Data sharing statement Data are freely available upon request.

Open access This is an open access article distributed in accordance with the Creative Commons Attribution Non Commercial (CC BY-NC 4.0) license, which permits others to distribute, remix, adapt, build upon this work non-commercially, and license their derivative works on different terms, provided the original work is properly cited, appropriate credit is given, any changes made indicated, and the use is non-commercial. See: http://creativecommons.org/licenses/by-nc/4.0

\section{REFERENCES}

1. Black MM, Hurley KM. Investment in early childhood development. The Lancet 2014;384:1244-5.
2. Walker SP, Wachs TD, Meeks Gardner J, et al. Child development: risk factors for adverse outcomes in developing countries. The Lancet 2007;369:145-57.

3. Grantham-McGregor S, Cheung YB, Cueto S, et al. Developmental potential in the first 5 years for children in developing countries. The Lancet 2007;369:60-70.

4. Shonkoff JP, Garner AS. The committee on psychosocial aspects of child and family health, committee on early childhood, adoption, and dependent care, and section on developmental and behaviora pediatrics. The lifelong effects of early childhood adversity and toxic stress. Pediatrics 2011;129:232-46.

5. Walker SP, Wachs TD, Grantham-McGregor S, et al. Inequality in early childhood: risk and protective factors for early child development. The Lancet 2011;378:1325-38.

6. World Health Organization, 2015. The WHO child growth standards. Available from: http://www.who.int/childgrowth/en/ [Accessed $8 \mathrm{Apr}$ 2015].

7. Murray CJL, Ezzati M, Flaxman AD, et al. GBD 2010: design, definitions, and metrics. The Lancet 2012;380:2063-6.

8. Stevens GA, Finucane MM, Paciorek CJ, et al. Trends in mild, moderate, and severe stunting and underweight, and progress towards MDG 1 in 141 developing countries: a systematic analysis of population representative data. The Lancet 2012;380:824-34.

9. World Health Organization, 2016. Nutrition Landscape Information System (NLiS). Available from: http://apps.who.int/nutrition/ landscape/search.aspx

10. United Nations Population Division, 2015. World population prospects: 2015 revision. Available from: http://www.un.org/en/ development/desa/population/events/other/10/index.shtml

11. Charmandari E, Kino T, Souvatzoglou E, et al. Pediatric stress: hormonal mediators and human development. Hormone Research in Paediatrics 2003;59:161-79.

12. Reyes $H$, Pérez-Cuevas $R$, Sandoval $A$, et al. The family as a determinant of stunting in children living in conditions of extreme poverty: a case-control study. BMC Public Health 2004;4:57.

13. Surkan PJ, Kennedy CE, Hurley KM, et al. Maternal depression and early childhood growth in developing countries: systematic review and meta-analysis. Bull World Health Organ 2011;89:608-15.

14. Fink G, Sudfeld CR, Danaei G, et al. Scaling-up access to family planning may improve linear growth and child development in low and middle income countries. PLoS One 2014;9:e102391.

15. Chai J, Fink G, Kaaya S. Intimate partner violence (IPV) is negatively associated with child development in low and middle income countries - evidence from the demographic and health survey program. Bull World Health Organ 2016;94:331-9.

16. Finlay JE, Fink G, McCoy DC, et al. Stunting risk of orphans by caregiver and living arrangement in low-income and middle-income countries. J Epidemiol Community Health 2016;70:784-90.

17. Barro RJ, Lee JW, 2013. Barro-Lee educational attainment dataset. Available from: http://www.barrolee.com/

18. 2015. Education, reconstruction, and projections - education, reconstruction \& projections - IIASA. Available from: http://www. iiasa.ac.at/web/home/research/researchPrograms/WorldPopulation/ Research/ForecastsProjections/DemographyGlobalHumanCapital/ EducationReconstructionProjections/education_reconstruction_and projections.html [Accessed 25 Apr 2015].

19. Ferrari AJ, Charlson FJ, Norman RE, et al. Burden of depressive disorders by country, sex, age, and year: findings from the Global Burden of Disease Study 2010. PLoS Med 2010;10:e1001547.

20. Ezzati M, Lopez AD, Rodgers A. Comparative quantification of health risks. Geneva: World Health Organization, 2002.

21. Lim SS, Vos T, Flaxman AD, et al. A comparative risk assessment of burden of disease and injury attributable to 67 risk factors and risk factor clusters in 21 regions, 1990-2010: a systematic analysis for the Global Burden of Disease Study 2010. The Lancet 2012;380:2224-60.

22. Danaei G, Andrews KG, Sudfeld CR, et al. Risk factors for childhood stunting in 137 developing countries: a comparative risk assessment analysis at global, regional, and country levels. PLoS Med 2016;13:e1002164

23. Kabir ZN, Nasreen H-E, Edhborg M. Intimate partner violence and its association with maternal depressive symptoms 6-8 months after childbirth in rural Bangladesh. Glob Health Action 2014;7:24725.

24. Fonseca-Machado MO, Alves LC, Monteiro JC, et al. Depressive disorder in pregnant Latin women: does intimate partner violence matter? J Clin Nurs 2015;24(9-10):1289-99.

25. United Nations, 2016. Millennium development indicators: world and regional groupings [Internet]. Available from: http://mdgs.un.org/ unsd/mdg/Host.aspx?Content=Data/RegionalGroupings [Accessed 24 Apr 2016]. 
26. Fink G, Peet E, Danaei G, et al. Schooling and wage income losses due to early-childhood growth faltering in developing countries: national, regional, and global estimates. Am J Clin Nutr 2016:104:104-12.

27. Frost MB, Forste R, Haas DW. Maternal education and child nutritional status in Bolivia: finding the links. Soc Sci Med 2005;60:395-407.

28. Marphatia AA, Cole TJ, Grijalva-Eternod C, et al. Associations of gender inequality with child malnutrition and mortality across 96 countries. Glob Health Epidemiol Genom 2016;1:e6.

29. Richards E, 2011. Gender influences on child survival, health and nutrition: a narrative review. Available from: https://www.unicef org/Gender_Influences_on_Child_Survival_a_Narrative_review.pdf [Accessed Dec 2011].

30. Rodríguez L. Intrahousehold inequalities in child rights and wellbeing. A barrier to progress? World Development 2016;83:111-34.

31. Abramsky T, Watts $\mathrm{CH}$, Garcia-Moreno $\mathrm{C}$, et al. What factors are associated with recent intimate partner violence? findings from the WHO multi-country study on women's health and domestic violence. BMC Public Health 2011;11:109.

32. Pronyk PM, Hargreaves JR, Kim JC, et al. Effect of a structural intervention for the prevention of intimate-partner violence and HIV in rural South Africa: a cluster randomised trial. The Lancet 2006;368:1973-83.

33. Baral YR, Lyons K, Skinner J. Determinants of skilled birth attendants for delivery in Nepal. Kathmandu Univ Med J 2010;8:325-32.

34. Miyake Y, Tanaka K, Sasaki S, et al. Employment, income, and education and risk of postpartum depression: the Osaka Maternal and Child Health Study. J Affect Disord 2011;130(1-2):133-7.

35. Beck CT. Predictors of postpartum depression: an update. Nurs Res 2001;50:275-85.
36. Alvarado-Esquivel C, Sifuentes-Alvarez A, Salas-Martinez C. Validation of the edinburgh postpartum depression scale in a population of adult pregnant women in Mexico. J Clin Med Res 2014;6:374-8.

37. Rahman A, Fisher J, Bower P, et al. Interventions for common perinatal mental disorders in women in low- and middle-income countries: a systematic review and meta-analysis. Bull World Health Organ 2013;91:593-601.

38. Huddleston-Casas C, Charnigo R, Simmons LA. Food insecurity and maternal depression in rural, low-income families: a longitudinal investigation. Public Health Nutr 2009;12:1133.

39. Hadley C, Patil CL. Food insecurity in rural Tanzania is associated with maternal anxiety and depression. Am J Hum Biol 2006;18:359-68.

40. Gebreyesus SH, Endris BS, Hanlon C, et al. Maternal depression symptoms are highly prevalent among food-insecure households in Ethiopia. Public Health Nutr 2018;21:849-56.

41. Schmeer KK, Piperata BA, Rodríguez AH, Herrera Rodríguez A, et al. Maternal resources and household food security: evidence from Nicaragua. Public Health Nutr 2015;18:2915-24.

42. Perumal N, Bassani DG, Roth DE. Use and Misuse of Stunting as a Measure of Child Health. J Nutr 2018;148:311-5.

43. Christian P, Lee SE, Donahue Angel M, et al. Risk of childhood undernutrition related to small-for-gestational age and preterm birth in low- and middle-income countries. Int $J$ Epidemiol 2013;42:1340-55.

44. Futures Group, 2018. Spectrum. Available from: http://futuresgroup. com/resources/software models/spectrum

45. Devries KM, Mak JY, García-Moreno C, et al. Global health. The global prevalence of intimate partner violence against women. Science 2013;340:1527-8. 